\title{
TITLE:
}

\section{$<$ NOTE>An Old Female Bonobo Carried a Dead Red-Tailed Monkey for over a Month}

\section{$\operatorname{AUTHOR}(S)$ :}

Toda, Kazuya; Tokuyama, Nahoko; Furuichi, Takeshi

\section{CITATION:}

Toda, Kazuya ...[et al]. < NOTE>An Old Female Bonobo Carried a Dead Red-Tailed Monkey for over a Month. Pan Africa News 2017, 24(2): 19-21

ISSUE DATE:

2017-12

URL:

http://hdl.handle.net/2433/228896

RIGHT:

Copyright (C) Pan Africa News. 
https://doi.org/10.1002/ajpa.23269

Collins DA, McGrew WC 1988. Habitats of 3 groups of chimpanzees (Pan troglodytes) in western Tanzania compared. J Hum Evol 17:553-574. https://doi.org/10.1016/0047-2484(88)90084-X

Fragaszy DM, Perry S (eds) 2003. The Biology of Traditions: Models and Evidence. Cambridge University Press, Cambridge, UK

Goodall J 1964. Tool using and aimed throwing in a community of free-living chimpanzees. Nature 201:1264-1266. https://doi.org/10.1038/2011264a0

Haslam M, Hernandez-Aguilar A, Arroyo A et al. 2017. Primate archaeology evolves. Nat Ecol Evol 1:1431-1437. https://doi.org/10.1038/s41559-017-0286-4

Haslam M, Luncz L, Pascual-Garrido A et al. 2016. Archaeological excavation of wild macaque stone tools. $J$ Hum Evol 96:134-138. https://doi.org/10.1016/j.jhevol.2016.05.002

Hobaiter C, Poisot T, Zuberbühler K, Hoppitt W, Gruber T 2014. Social network analysis shows direct evidence for social transmission of tool use in wild chimpanzees. PLoS Biol 12:e1001960. https://doi.org/10.1371/journal.pbio.1001960

McBeath NM, McGrew WC 1982. Tools used by wild chimpanzees to obtain termites at Mt Assirik, Senegal: The influence of habitat. J Hum Evol 11:65-72.

https://doi.org/10.1016/S0047-2484(82)80032-8

McGrew WC 1992. Chimpanzee Material Culture: Implications for Human Evolution. Cambridge University Press, Cambridge, UK.

McGrew WC, Collins, DA 1985. Tool use by wild chimpanzees (Pan troglodytes) to obtain termites (Macrotermes herus) in the Mahale Mountains, Tanzania. Am J Primatol 9:47-62.

https://doi.org/10.1002/ajp.1350090106

Musgrave S, Morgan D, Lonsdorf E, Mundry R, Sanz C 2016. Tool transfers are a form of teaching among chimpanzees. Sci Rep 6:34783.

https://doi.org/10.1038/srep34783

Nakamura M, Corp N, Fujimoto M et al. 2013. Ranging behavior of Mahale chimpanzees: A 16 year study. Primates 54:171-182. https://doi.org/10.1007/s10329-012-0337-z

Nishida T 1968. The social group of wild chimpanzees in the Mahali mountains. Primates 9:167-224. https://doi.org/10.1007/BF01730971

Nishida T, Uehara S 1980. Chimpanzees, tools and termites: Another example from Tanzania. Curr Anthropol 5:671-672. https://doi.org/10.1086/202545

O’Malley RC, Wallauer W, Murray CM, Goodall J 2012. The appearance and spread of ant fishing among the Kasekela chimpanzees at Gombe. Curr Anthropol 53:650-663. https://doi.org/10.1086/666943

Pascual-Garrido A 2017. Termite fishing tools of wild chimpanzees and source plant scars: Towards an archaeology of the perishable. Manuscript submitted for publication.

Pascual-Garrido A, Buba U, Nodza G, Sommer V 2012. Obtaining raw material: Plants as tool sources for Nigerian chimpanzees. Folia Primatol 83:24-44. https://doi.org/10.1159/000338898

Piel AK, Stewart FA, Pintea L et al. 2013. The Malagarasi river does not form an absolute barrier to chimpanzee movement in Western Tanzania. PLoS One 8:e58965. https://doi.org/10.1371/journal.pone.0058965

Sanz CM, Deblauwe I, Tagg N, Morgan DB 2014. Insect prey characteristics affecting regional variation in chimpanzee tool use. J Hum Evol 71:28-37. https://doi.org/10.1016/j.jhevol.2013.07.017

Sanz CM, Morgan DB 2007. Chimpanzee tool technology in the Goualougo Triangle, Republic of Congo. J Hum Evol 52:420-433. https://doi.org/10.1016/j.jhevol.2006.11.001

Sanz CM, Morgan DB, Gulick S 2004. New insights into chimpanzees, tools and termites from the Congo Basin.
Am Nat 164:567-581.

https://doi.org/10.1086/424803

Teleki G 1974. Chimpanzee subsistence technology: Materials and skills. J Hum Evol 3:575-594.

https:///doi.org/10.1016/0047-2484(74)90018-9

Uehara S 1982. Seasonal changes in the techniques employed by wild chimpanzees in the Mahale Mountains, Tanzania, to feed on termites (Pseudocanthotermes spiniger). Folia Primatol 37:44-76. https://doi.org/101159/000156020

\section{<NOTE>}

\section{An Old Female Bonobo Carried a Dead Red-Tailed Monkey for over a Month}

\author{
Kazuya Toda ${ }^{1}$, Nahoko Tokuyama ${ }^{2}$ \\ \& Takeshi Furuichi ${ }^{1}$ \\ 1 Primate Research Institute, Kyoto University, Japan \\ 2 The Graduate University for Advanced Studies, Japan \\ (E-mail: toda.kazuya.78x@st.kyoto-u.ac.jp)
}

\section{INTRODUCTION}

Carrying infants is one of the most important maternal tasks determining the survival of dependent infants in non-human primates (Nicolson 1987; Ross 2001). Even after the death of their infants, mothers tend to carry the carcasses for several days, and even up to several months (Hosaka et al. 2000; Sugiyama et al. 2009; Tokuyama et al. 2017). Such prolonged carrying can be considered as "maternal persistency" (Sugiyama et al. 2009; Biro et al. 2010).

Excluding mothers that carry their infants, nonhuman primates rarely carry objects for a long period, (Ross 2001; Carvalho et al. 2012). However, at Wamba in Democratic Republic of the Congo, we observed that an old female bonobo (Pan paniscus) carried the carcass of a red-tailed monkey (Cercopithecus ascanius) for over a month. We here report occasional observations of her behaviors and conditions of the monkey carcass, and discuss why she had been persistent with the dead body of another primate.

\section{SITE AND SUBJECT}

Observations were made in 2016 at Wamba, Luo Scientific Reserve, Democratic Republic of Congo, which is a long-term field site for the study of wild bonobos (Kano 1992). There are two adjacent groups of bonobos, the eastern group (PE) and the western group (PW), of which all members were fully habituated and identified. We usually followed the PE group from one night's bed sites (around 06:00 h) to the next night's bed sites (around 17:00 h), and occasionally observed the PW group especially during inter-group encounters. The adult female reported in the present study, Chio (estimated to be $45-50$ years old), had been identified in the PW group together with her daughter (Chacha: estimated to be 7-8 years old) in September 2012. Since then, Chio had not been observed to have an infant. 


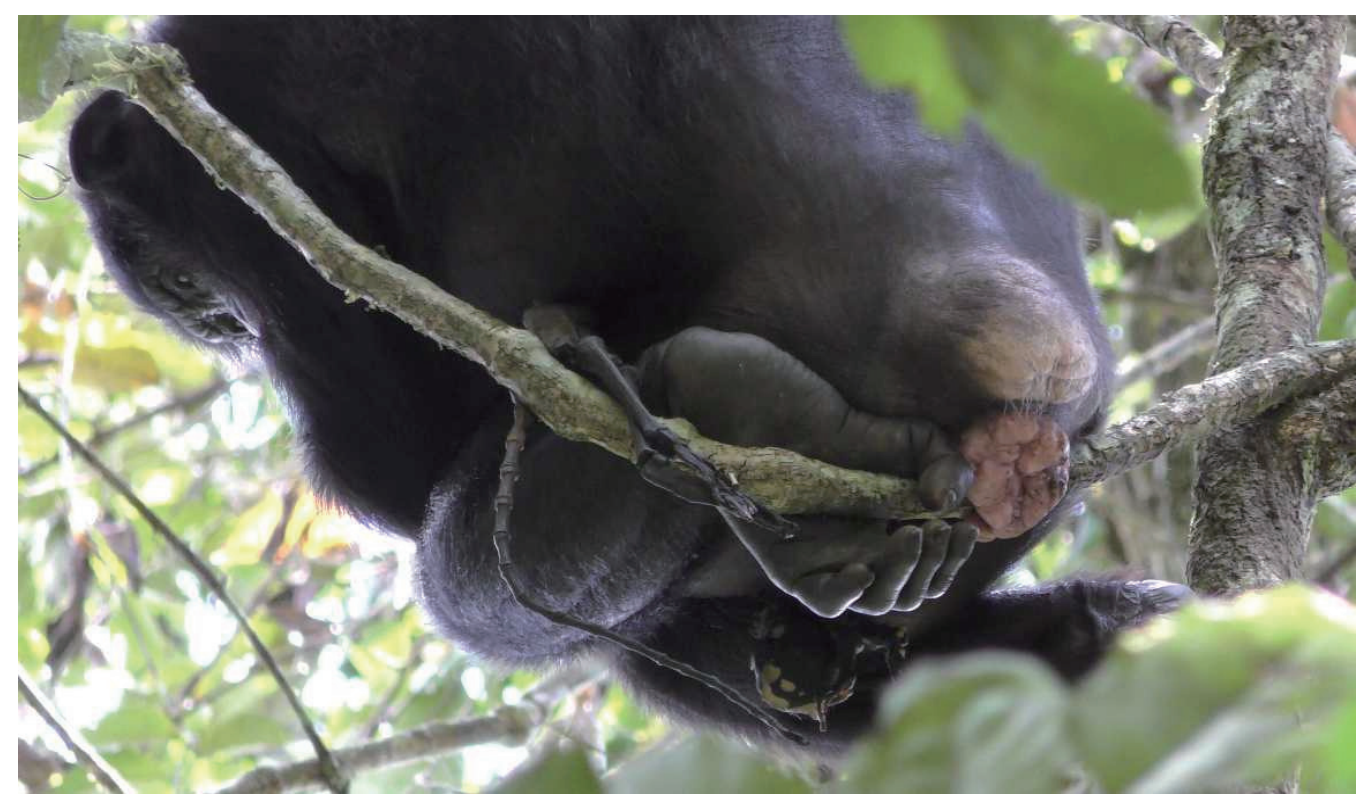

Figure 1. Chio resting on a tree with a mummified red-tailed monkey.

\section{OBSERVATIONS}

On August 18, we found that Chio was carrying the dead body of a red-tailed monkey at 13:47 h. The monkey carcass seemed to be an adult based on size, which was as large as infant bonobos at one or two years of age. It did not have any visible external injury and retained its head, all limbs, tail, and fur. It was suspected to have died several days before the observation because it had already decayed and emitted a decomposing odor to the observers. When Chio rested with the carcass on a tree at 14:00 h, two adult males approached her to watch it but did not try to take it. At 14:34 h, Chio hung it on her neck like a muffler and moved away with it.

On August 25, we found that Chio was with the monkey carcass at 13:40 h, but we could observe her only once on that day.

On August 29, we found that Chio walked on the ground with the carcass hanging on her neck at 12:46 $h$. The decay of the carcass was proceeding. Little fur remained and it was dried up from the head to the tail, including all the limbs. Chio grasped the carcass in her hand and engaged in genito-genital rubbing with another adult female at 12:48 $\mathrm{h}$, then she moved away hanging it on her neck.

On August 31, we found Chio resting on a tree with the carcass hung around her neck at 06:43 h. One infant approached Chio apparently to play with the carcass at 07:13 $\mathrm{h}$ and Chio moved the carcass from her neck onto her abdominal region to prevent the infant from touching the carcass. At 07:21 h after the infant left, Chio lifted the head of the carcass to eye level and gazed at it for about five minutes. She groomed it for two minutes at $07: 36 \mathrm{~h}$, occasionally flapping flies gathering around it, and moved away with it at 07:40 h.

On September 17, we found that Chio had the mummified monkey at $1649 \mathrm{~h}$, but we only caught a glimpse of her once before members made night beds.

On September 21, we found Chio was still in possession of the carcass at 07:14 h. The monkey carcass was fully mummified. When she engaged in genito-genital rubbing with another adult female and a juvenile female at 07:34 h, she grasped the mummy in her hand. Then, she rested and held the mummy in her abdominal region at $07: 40 \mathrm{~h}$ (Figure 1, also see Video 1 available online at http://mahale.main.jp/PAN/24_2/24(2)_04.html). One infant approached her and watched the mummy at 07:56 h. She suddenly grabbed the arm of the infant, and the infant ran away screaming. Chio groomed the mummy with her mouth at 08:49 h, and moved away with it hanging on her neck.

On September 29 and 30, we found that Chio still walked with the mummy hanging around her neck at 11:23h and13:40h. The mummy was intact until our last observation.

On October 25, we found Chio within members of the PW group at 10:18 h, but she was no longer carrying the monkey carcass.

\section{DISCUSSION}

Chio had carried the dead red-tailed monkey for at least 43 days without a motivation of preying or playing, although we did not observe how she got and released it. She was observed to groom the hair of the monkey carcass, gaze at its body, and defend it from curious juveniles. She seemed to handle the monkey carcass carefully and protectively even during it had been decaying. Her behaviors towards the decaying monkey carcass could be considered similar to the behaviors of mothers carrying their dead infants with great care (Kano 1992; Hosaka et al. 2000; Sugiyama et al. 2009; Biro et al. 2010; Tokuyama et al. 2017).

Few observations of non-human primates carrying bodies of other animal species for a long time have been reported until date. In chimpanzees, however, a barren female carried a limb of dead dried red colobus (Procolobus rufomitratus) for seven hours at Mahale (Hosaka et al. 2000), and an adolescent female carried a dead hyrax (Dendrohyrax dorsalis) for fifteen hours, slept with it in her nest, and groomed it at Bossou (Hirata et al. 2001). 
These observations might indicate that their imagination could make an unusual perception and reaction towards other animal species.

Allomothering, defined as temporary carrying of non-kin infants is performed mostly by non-parous young females, which has been suggested to be a process of acquiring maternal skills in non-human primates (McKenna 1979). However, it is occasionally conducted by adult parous females without their own infants (Nozaki 2009; Tokuyama 2015). Chio's case fits the latter well, because she had not cared her own infants for a long time. The unusual carrying might have been a coincidence induced by the maternal drive for infant caring.

\section{ACKNOWLEDGMENTS}

We sincerely thank the Ministry of Scientific Research of the Democratic Republic of Congo for granting permission to conduct research on bonobos and the Research Center on Ecology and Forestry (CREF) in the Democratic Republic of Congo for supporting our research in the Luo Scientific Reserve. We sincerely thank Dr. Sakamaki for his great contribution to continuous observations and camp management at Wamba and the local assistants for their helps of our observations. Field research of KT was financially supported by Leading Program of Primatology and Wildlife Science (PWS) of Kyoto University and Grant-in-Aid for JSPS Fellows (17J01336), Japan.

\section{REFERENCES}

Biro D, Humle T, Koops K et al. 2010. Chimpanzee mothers at Bossou, Guinea carry the mummified remains of their dead infants. Curr Biol 20:R351-R352. https://doi.org/10.1016/i.cub.2010.02.031

Carvalho S, Biro D, Cunha E, Matsuzawa T 2012. Chimpanzee carrying behavior and the origins of human bipedality. Curr Biol 22:180-181. https://doi.org/10.1016/j.cub.2012.01.052

Hirata S, Yamakoshi G, Fujita S, Ohashi G, Matsuzawa T 2001. Capturing and toying with hyraxes (Dendrohyrax dorsalis) by wild chimpanzees (Pan troglodytes) at Bossou, Guinea. Am J Primatol 53:93-97. https://doi.org/10.1002/1098-2345(200102)53:2<93:-AID-AJP5>3.0.CO:2-X

Hosaka K, Matsumoto-Oda A, Huffman MA, Kawanaka K 2000. Reactions to dead bodies of conspecifics by wild chimpanzees in the Mahale Mountains, Tanzania. Primate Res 16:1-15, in Japanese with an English summary. https://doi.org/10.2354/psj:16.1

Kano T 1992. The Last Ape: Pygmy Chimpanzee Behavior and Ecology. Stanford University Press, Stanford, CA.

McKenna JJ 1979. The evolution of allomothering behavior among colobine monkeys: Function and opportunism in evolution. Am Anthropol 81:818-840. https://doi.org/10.1525/aa.1979.81.4.02a00040

Nicolson NA 1987. Infants, mothers and others females. In: Primates Societies. Smuts BB, Cheney DL, Seyfarth RM, Wrangaham RW, Struhsaker TT (eds), The University of Chicago Press, Chicago, pp. 330-342.

Nozaki M 2009. Grandmothers care for orphans in a provisioned troop of Japanese macaques (Macaca fuscata). Primates 50:85-88. https://doi.org/10.1007/s10329-008-0118-x

Ross C 2001. Park or ride?: Evolution of infant carrying in primates. Int J Primatol 22:749-771. https: $/ /$ doi.org/10.1023/A:1012065332758

Sugiyama Y, Kurita T, Matsui T, Kimoto S, Shimomura $\mathrm{T}$ 2009. Carrying of dead infants by Japanese macaque (Macaca fuscata) mothers. Anthropol Sci 117:113-119. https://doi.org/10.1537/ase.080919

Tokuyama N 2015. A case of infant carrying against the mother's will by an old adult female bonobo at Wamba, Democratic Republic of Congo. Pan Afr News 22:15-17. https://doi.org/2433/203112

Tokuyama N, Moore DL, Graham KE, Lokasola A, Furuichi $\mathrm{T}$ 2017. Cases of maternal cannibalism in wild bonobos (Pan paniscus) from two different field sites, Wamba and Kokolopori, Democratic Republic of the Congo. Primates 58:7-12.

https://doi.org/10.1007/s10329-016-0582-7

\section{<BOOK REVIEW> Cannibalism: A Perfectly Natural History}

By Bill Schutt

Chapel Hill, NC: Algonquin Books, 332 pp.

ISBN: 978-1-61620-462-4, 2017. \$26.95 (USA), paperback

\author{
William C. McGrew \\ School of Psychology \& Neuroscience, University of St \\ Andrews, Scotland, UK \\ (E-mail:wcm2@st-and.ac.uk)
}

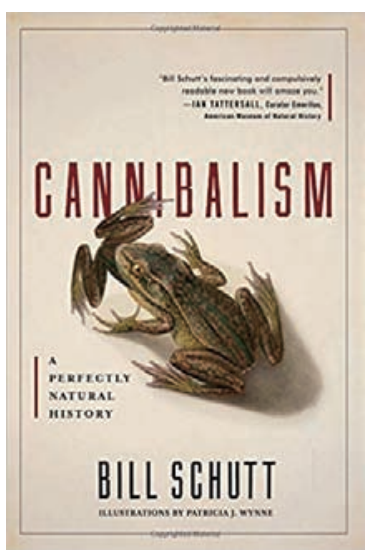

Given that chimpanzees have shown more instances of cannibalism than all other species of non-human primates combined, and also that chimpanzees are the mostinvoked species for modelling the evolutionary origins of human behaviour, this book seemed worth scrutinising. Furthermore, the sub-title suggests a natural science viewpoint, rather than the more usual social science (i.e., anthropology) viewpoint, as does the author's status as a vertebrate zoologist (on the faculty of Long Island University, USA). For comparative contrast, see what may be the best previous example of tackling the topic, Petrinovich's (2000) The Cannibal Within, in which nonhuman cannibalism gets only $5 \mathrm{pp}$.

First, the structure and format. Schutt does not do research on cannibalism but instead summarises and synthesises findings on the topic. But he goes beyond reading and analysing published material by travelling to interview researchers in situ, with participant observation that entails (e.g.) archaeology and anthropophagy. (Yes, he eats human tissue.) About this, he writes accessibly but academically (e.g., providing scientific names for taxa), with a light touch enlivened by humour. Good points are: 28 pages of endnotes by text page number, which provide references to publications; an extensive book list $(\mathrm{n}=68)$, 